\title{
DESEMPENHO, CARCAÇA E CORTES DE FRANGOS CAIPIRA FRANCÊS BARRÉ (GRIS BARRÉ COU PLUMÉ)"
}

\author{
PERFORMANCE, CARCASS AND CUTS OF BROILERS CAIPIRA FRANCÊS BARRÉ \\ (GRIS BARRÉ COU PLUMÉ)
}

\author{
Santos, M.S.V. dos $^{1 *}$, Vieira, S.S. ${ }^{1}$, Tavares, F.B. ${ }^{1}$, Andrade, P. de A. ${ }^{1}$, Manno, M.C. ${ }^{2}$, \\ Costa, H.S. da ${ }^{1}$ e Moreira, A. da S. ${ }^{3}$
}

'Universidade Federal Rural da Amazônia. Campus de Parauapebas, PA. Brasil. *maria.vieira@ufra.edu.br ${ }^{2}$ Universidade Federal Rural da Amazônia. Campus de Belém, PA. Brasil.

${ }^{3}$ Secretaria de Produção Rural de Parauapebas-SEMPROR. Parauapebas, PA. Brasil.

\section{PaLAVRAS ChaVE ADICIONAIS}

Consumo de ração. Exigência nutricional.

\section{RESUMO}

Objetivou-se analisar os efeitos dos níveis de energia metabolizável e da idade de abate sobre o desempenho zootécnico, rendimento de carcaça e cortes de frangos da linhagem Caipira Francês Barré. O experimento foi conduzido em galpão experimental localizado em Parauapebas, PA. Foram utilizados 192 pintos, mistos, de 1 dia, criados em sistema intensivo. $O$ delineamento experimental utilizado foi inteiramente casualizado, com 3 tratamentos. Cada tratamento foi formado de 4 repetições, sendo a unidade experimental 1 box de 16 aves. Os tratamentos foram definidos de acordo com os níveis de energia metabolizável das rações inicial (1 a 28 dias) e final (29 a 90 dias), respectivamente: T1 - 3000 e $3100 \mathrm{kcal}$ de $\mathrm{EM} / \mathrm{kg}$; T2 - 3100 e $3200 \mathrm{kcal}$ de EM/kg; T3 - 3200 e 3300 $\mathrm{kcal}$ de EM/kg. As variáveis estudadas foram peso inicial, peso final, consumo de ração e conversão alimentar, proteína bruta consumida, proteína metabolizada consumida, eficiência energética e eficiência protéica. As características de carcaças das aves, analisadas com 77, 84 e 91 dias de idade, foram o rendimento de carcaça, peito, coxas, sobrecoxas, asa, dorso, asas, pés, cabeça e pescoço. A análise estatística dos dados foi realizada utilizando o procedimento ANOVA, para um modelo inteiramente casualizado, com o pro-

"Projeto financiado pelo Conselho Nacional de Desenvolvimento Científico e Tecnológico-CNPq.

Recibido: 11-5-11. Aceptado: 22-12-11.

\section{AdDTIONAL KEYWORDS}

Feed intake. Nutritional requirement.

grama Sistema para análise estatística e genética (SAEG, 2007). As diferenças entre as médias das variáveis estudadas foram realizadas pelo Teste de Tukey a um nível de $5 \%$. Os níveis de energia nas dietas não interferiram no desempenho zootécnico e no rendimento de carcaça, peito, coxas, sobrecoxas, asas, pés e cabeça + pescoço das aves. O nível de $3200 \mathrm{kcal}$ de $\mathrm{EM} / \mathrm{kg}$ proporcionou melhor rendimento de dorso. A proteína bruta e a energia metabolizada consumida pelas aves melhoraram com o incremento energético da ração, durante a fase de engorda. A idade de abate não influenciou no rendimento de carcaça, entretanto as aves abatidas aos 90 dias de idade apresentaram maior rendimento de peito.

\section{SUMMARY}

This study aimed to analyze the effects of metabolizable energy levels and the age at slaughter on growth performance, carcass yield and cuts broilers Caipira French Barré. The experiment was conducted in Parauapebas, PA. We used 192 one day chicks reared in intensive system. The experimental design was completely randomized with three treatments. Each treatment consisted of four replications, the experimental unit being a box of 16 birds. The treatments were defined according to the levels of metabolizable energy diets ( 1 to 28 days) and late (29 to 90 days), 


\section{SANTOS, VIEIRA, TAVARES, ANDRADE, MANNO, COSTAE MOREIRA}

respectively: T1 - 3000 and $3100 \mathrm{kcal}$ of $\mathrm{ME} / \mathrm{kg}, \mathrm{T} 2$ - 3100 and $3200 \mathrm{kcal} / \mathrm{kg}, \mathrm{T} 3-3200$ and $3300 \mathrm{kcal}$ of ME $/ \mathrm{kg}$. The variables studied were initial weight, final weight, feed intake and feed conversion, protein consumed, metabolized protein consumed, energy efficiency and protein efficiency. The characteristics of carcasses of birds, analyzed with 77,84 and 91 days of age were the carcass, breast, thigh, drumstick, wing, back, wings, feet, head and neck. The statistical analysis was performed using the ANOVA procedure for a completely randomized model with the System for statistical analysis and genetics (SAEG, 2007). Differences between means of variables were performed by Tukey's test at a level of $5 \%$. The energy levels in the diets did not affect on the performance and carcass yield, breast, thighs, drumsticks, wings, feet and head + neck in birds. The level of 3200 $\mathrm{kcal} / \mathrm{kg}$ provided better yield back. The protein and metabolic energy consumed by the birds improved with higher energy content of feed during the fattening stage. Age at slaughter did not affect carcass yield, however the birds slaughtered at 90 days of age showed higher breast yield.

\section{INTRODUÇÃO}

As criações domésticas de galinha Caipira, praticadas nas unidades agrícolas familiares, se caracterizam pela sua forma de exploração extensiva, onde as práticas de manejo não envolvem eficientemente os aspectos reprodutivos, nutricionais e sanitários. Tal fato resulta em índices de fertilidade e natalidade reduzidos (Sagrilo et al., 2003). Essa ave, conhecida por Caipira (região Sudeste), Colonial (região Sul) ou Capoeira (região Nordeste) tem características sensoriais diferenciadas das aves criadas em confinamento comercial, com carne mais escura e firme, sabor acentuado e menor teor de gordura na carcaça (Takahashi et al., 2006). A produção de carne tipo caipira é um dos segmentos da avicultura alternativa que tem se mostrado promissor, tendo em vista a fatia do mercado composta por consumidores que demandam por produtos mais saborosos (Santos et al., 2005).

O conhecimento da composição química e energética dos ingredientes utilizados na formulação de rações é necessário para que se produzam rações com níveis nutricionais adequados para suprir as exigências dos animais, sem excesso ou deficiência, e permitir máxima produtividade (Mello et al., 2009). Com o grande avanço na produção avícola, principalmente na produção de frangos de corte, torna-se necessária a busca por alternativas que possibilitem a formulação de rações mais eficientes e econômicas, uma vez que a alimentação representa 70 a $80 \%$ do custo. Neste sentido, os efeitos de níveis de energia metabolizável sobre o desempenho de frangos de corte são constantemente avaliados, pois são os itens que mais oneram as rações (Duarte et al., 2006).

A energia que os animais obtêm dos alimentos é utilizada prioritariamente para a manutenção dos processos vitais, como respiração, manutenção da temperatura corporal e fluxo sangüíneo. A energia extra consumida pelos animais é depositada como tecido corporal (Neto et al., 2000). Nesse contexto, a literatura tem mostrado que o desempenho das aves tem relação direta com o nível de energia da ração. Entretanto, poucas pesquisas para estudar exigências de energia para aves de crescimento lento foram realizadas até o momento. De acordo com Zanusso e Dionello (2003), seria impossível criar até 12 semanas de idade uma linhagem com crescimento rápido, pois seu peso seria demasiadamente elevado, sua taxa de engorda excessiva, piorando a conversão alimentar, além de apresentar mortalidade elevada e possíveis problemas locomotores. Em geral, dietas com altos teores de energia proporcionam carcaças mais gordas, enquanto dietas com alto teor de proteína ocasionam carcaças mais magras (Kolling et al., 2005).

O presente estudo teve por objetivo avaliar o efeito dos níveis de energia metabolizável da ração sobre o desempenho, rendimento e características de carcaça e órgãos de frangos da linhagem Caipira Francês Barré. 


\section{DESEMPENHO, CARCAÇA E CORTES DE FRANGOS CAIPIRA FRANCÊS BARRÉ}

\section{MATERIALEMÉTODOS}

A pesquisa foi desenvolvida em um galpão experimental cedido para a Universidade Federal Rural da Amazônia - UFRA, localizado em Parauapebas, PA.

Foram alojados 192 pintos de corte da linhagem Caipira Francês Barré (Gris Barré Cou Plumé), machos e fêmeas, com 1 dia de idade. As aves foram divididas em 12 boxes, contendo 16 animais cada, criados em sistema intensivo, com densidade de 6,4 aves/ $\mathrm{m}^{2}$. O período experimental teve duração de 90 dias.

O delineamento experimental foi inteiramente casualizado, com três tratamentos e quatro repetições de 16 aves cada. Os tratamentos foram definidos de acordo com os níveis de energia metabolizável das rações inicial ( 1 a 28 dias) e final ( 29 a 90 dias), respectivamente: T1 - 3000 e $3100 \mathrm{kcal}$ de $\mathrm{EM} / \mathrm{kg}$; T2 - 3100 e $3200 \mathrm{kcal}$ de $\mathrm{EM} / \mathrm{kg}$; $\mathrm{T} 3$ - 3200 e $3300 \mathrm{kcal} \mathrm{de} \mathrm{EM} / \mathrm{kg}$.

As rações foram formuladas à base de componentes convencionais, tais como milho, farelo de soja, farinha de carne, óleo de soja, calcário, fosfato bicálcico e cloreto de sódio. $\mathrm{O}$ atendimento das necessidades em vitaminas e minerais foi possível através da adição de premix vitamínicos e minerais comerciais, recomendados para frango de corte nas fases inicial e final. A composição das dietas experimentais na fase inicial e engorda estão apresentados nas tabelas I e II, respectivamente.

Antes do inicio do experimento o galpão e os equipamentos foram limpos e desinfetados. Logo após a chegada dos pintos no galpão experimental, realizou-se o manejo de seleção e pesagem. Lotes homogêneos de 16 pintos foram pesados e distribuídos aleatoriamente nos boxes, de acordo com a identificação dos tratamentos e repetições. Durante a fase experimental foram coletados no galpão dados meteorológicos de temperatura mínima e máxima e temperatura ambiente às 9:00 e 15:00 horas respectivamente.

Os pintos foram vacinados no incu- batório contra doenças de Marek e Bouba Aviária e receberam a vacina contra Newcastle aos 7 dias de idade. A água e a ração foram fornecidas à vontade. Os bebedouros foram lavados e cheios duas vezes por dias para evitar a redução do consumo de água e conseqüentemente de

Tabela I. Composição das dietas experimentais na fase inicial (1-28 dias). (Composition of experimental diets in the early phase (128 days)).

\begin{tabular}{lccc}
\hline Ingredientes (\%) & T1 & T2 & T3 \\
\hline Milho moído & 58,83 & 56,54 & 54,25 \\
Farelo de soja & 32,60 & 32,90 & 33,33 \\
Óleo vegetal & 1,80 & 3,70 & 5,60 \\
Farinha carne & 5,50 & 5,60 & 5,60 \\
Calcário calcítico & 0,37 & 0,36 & 0,35 \\
Sal comum & 0,30 & 0,30 & 0,30 \\
Premix* & 0,60 & 0,60 & 0,60 \\
Total & 100 & 100 & 100 \\
& \multicolumn{3}{c}{} \\
Composição nutricional calculada & \\
EM (kcal/kg) & 3000 & 3100 & 3200 \\
Proteína bruta \% & 22,00 & 22,00 & 22,00 \\
Extrato etéreo \% & 4,89 & 6,70 & 8,51 \\
Fibra bruta \% & 3,54 & 3,52 & 3,49 \\
Matéria mineral \% & 5,31 & 5,31 & 5,31 \\
Lisina \% & 1,21 & 1,22 & 1,23 \\
Cálcio \% & 1,00 & 1,00 & 1,00 \\
Fósforo total \% & 0,68 & 0,68 & 0,68 \\
Fósforo disponível \% & 0,48 & 0,48 & 0,48 \\
Sódio \% & 0,17 & 0,17 & 0,17 \\
\hline
\end{tabular}

EM: Energia metabolizável.

*Mineral/vitamínico. Composição por kg do produto: Vit. A - 1835000 UI; Vit. D3 - 335000 UI; Vit. E- 2835 mg; Vit. B1 - 335 mg; Vit. B2 - 1000 mg; Vit. B6 - 335 mg; Vit. K3 - 417 mg; Vit. B12 - $2500 \mu g$; Biotina 17 mg; Ácido fólico - 135 mg; Niacina - 6670 mg; Selênio - 35 mg; Antioxidante - 2000 mg; Pantontenato de cálcio - $1870 \mathrm{mg}$; Cobre - 1000 mg; Cobalto $35 \mathrm{mg}$; lodo - $170 \mathrm{mg}$; Ferro $8335 \mathrm{mg}$; Manganês - 10835 mg; Zinco - 8335 mg; Cloreto de colina 50\% - $135000 \mathrm{mg}$; Metionina - $267000 \mathrm{mg}$; Coccdiostático - $13335 \mathrm{mg}$; Promotor de crescimento - 16670 . 
Tabela II. Composição das dietas experimentais na fase final (29-90 dias). (Composition of experimental diets in the final stage (2990 days))

\begin{tabular}{lccc}
\hline Ingredientes (\%) & T1 & T2 & T3 \\
\hline Milho moído & 63,24 & 60,95 & 58,66 \\
Farelo de soja & 27,20 & 27,60 & 27,90 \\
Óleo vegetal & 2,60 & 4,50 & 6,40 \\
Farinha carne & 5,70 & 5,70 & 5,80 \\
Calcário calcítico & 0,36 & 0,35 & 0,34 \\
Sal comum & 0,30 & 0,30 & 0,30 \\
Premix* & 0,60 & 0,60 & 0,60 \\
Total & 100 & 100 & 100 \\
& & & \\
Composição nutricional calculada & \\
EM (kcal/kg) & 3100 & 3200 & 3300 \\
Proteína bruta \% & 20,00 & 20,00 & 20,00 \\
Extrato etéreo \% & 5,83 & 7,64 & 9,45 \\
Fibra bruta \% & 3,29 & 3,27 & 3,24 \\
Matéria mineral \% & 5,08 & 5,08 & 5,08 \\
Lisina \% & 1,07 & 1,08 & 1,08 \\
Cálcio \% & 1,00 & 1,00 & 1,00 \\
Fósforo total \% & 0,67 & 0,66 & 0,66 \\
Fósforo disponível \% & 0,48 & 0,48 & 0,48 \\
Sódio \% & 0,17 & 0,17 & 0,17 \\
& & & \\
\hline
\end{tabular}

EM: Energia metabolizável.

*Mineral/vitamínico. Composição por kg do produto: Vit. A-1335,000 UI; Vit. D3 - 300000 UI; Vit. E-2000 mg; Vit. B1 - 167 mg; Vit. B2 - 670 mg; Vit. B6 - 170

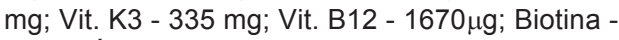
$7 \mathrm{mg}$; Ácido fólico - $67 \mathrm{mg}$; Niacina - $4670 \mathrm{mg}$; Selênio - 35 mg; Antioxidante - 2000 mg; Pantontenato de cálcio - $1870 \mathrm{mg}$; Cobre - $1000 \mathrm{mg}$; Cobalto $17 \mathrm{mg}$; lodo - $170 \mathrm{mg}$; Ferro $8335 \mathrm{mg}$; Manganês - 10835 mg; Zinco - 7500 mg; Cloreto de colina 50\% - 83340 mg; Metionina - 235000 mg; Coccdiostático - 10000 mg; Promotor de crescimento - 10000 .

ração. Forneceu-se 24 horas de luz através da utilização de lâmpadas fluorescentes instaladas no teto do galpão.

As variáveis estudadas foram o peso inicial, o peso final, o consumo de ração, a conversão alimentar, a proteína bruta consumida, a proteína metabolizada consumida, a eficiência energética e a eficiência protéica. As características de carcaças das aves, analisadas com 77, 84 e 91 dias de idade, foram o rendimento de carcaça, peito, coxas, sobrecoxas, asa, dorso, asas, pés, cabeça e pescoço.

Os dados de desempenho foram obtidos semanalmente e analisados nos períodos acumulados de 1 a 28 e 29 a 84 dias de idade. Para obtenção do peso corporal, as aves de cada boxe foram pesadas juntas no alojamento e semanalmente até 90 dias de idade. $\mathrm{O}$ ganho de peso foi obtido pela diferença entre peso final e peso inicial. $\mathrm{O}$ consumo de ração, pela diferença entre o total de ração consumida e as sobras de ração no final de cada período. A conversão alimentar foi calculada pela razão entre o total de ração consumida e o ganho de peso no período. O consumo de proteína bruta foi obtido através da multiplicação do consumo de ração pela composição centesimal de proteína bruta e dividido por 100 . O consumo de energia metabolizável foi obtido através da multiplicação da composição centesimal da energia metabolizável (kcal. $\mathrm{kg}^{-1}$ ) pelo consumo de ração. A eficiência protéica foi calculada pela diferença entre o consumo de proteína bruta e o ganho de peso e a eficiência energética pela multiplicação do consumo de energia metabolizável pelo consumo de ração.

Duas aves por repetição de cada tratamento foram abatidas aos 77, 84 e 90 dias de idade, após passarem por um jejum de 12 horas. Seguindo o processamento convencional de abate realizou-se a coleta dos dados da pesquisa. Os cortes de coxas, sobrecoxas, peito, asas, dorso, pés, cabeça e pescoço foram pesados em balança com precisão de $5 \mathrm{~g}$ e seus rendimentos calculados em relação ao peso da ave ao abate.

Os dados foram examinados estatísticamente por meio de análise de variância para um modelo inteiramente casualizado e as médias foram comparadas pelo teste de Tukey, a um nível de 5\% com o auxílio do programa Sistema para análise estatística e genética (SAEG, 2007). 


\section{DESEMPENHO, CARCAÇA E CORTES DE FRANGOS CAIPIRA FRANCÊS BARRÉ}

\section{RESULTADOSEDISCUSSÃO}

Os dados meteorológicos do galpão revelaram temperatura mínima de $24,5^{\circ}$, máxima de $32,6^{\circ}$, e ambiente de $28,4^{\circ} \mathrm{C}$ às $9: 00$ e 15:00 horas. Durante a fase experimental as aves não evidenciaram quadros de estresse e sintomas de enfermidades, apresentando nível de mortalidade compatível com a espécie.

Na fase inicial o peso médio, o consumo de ração, ganho de peso e a conversão alimentar não sofreram influência significativas $(p>0,05)$ pelos níveis de energia metabolizável das dietas (tabela III). Resultado divergente foi encontrado por Reginatto et al. (2000), que testando uma dieta com alto (3200 kcal/EM) e baixo ( $2900 \mathrm{kcal} / \mathrm{EM})$ nível de energia metabolizável em frangos de corte da linhagem Ross (1-21 dias de idade) reportaram que o desempenho dos frangos de corte foi reduzido nas aves que consumiram uma ração com energia menor.

A análise dos dados coletados revelou que na fase de engorda o peso médio, o ganho de peso e a conversão alimentar não foram influenciados pelos níveis de energia metabolizável das dietas. Aves alimentadas com dietas contendo 3200 e $3300 \mathrm{kcal}$ de $\mathrm{EM} / \mathrm{kg}$ obtiveram um maior consumo de ração e diferiram significativamente $(\mathrm{p}<0,05)$ da dieta com $3100 \mathrm{kcal} \mathrm{de} \mathrm{EM} / \mathrm{kg}$ (tabela III). Resultados semelhantes foram encontrados por Mendes et al. (2006) que alimentando frangos de corte da linhagem Coob, com uma dieta com níveis de energia entre 3020 e $3140 \mathrm{kcal}$ de EM/kg não observaram efeito significativo $(p>0,05)$ para o peso médio e ganho de peso. Por outro lado, Gomes et al. (2009), trabalhando com a mesma linhagem, observaram diferença significativa $(p<0,05)$ no ganho de peso das aves que consumiram ração com 2800 e $3000 \mathrm{kcal}$ de EM/kg. Na presente pesquisa, o Segundo Rostagno et al. (2005), os níveis de energia recomendados são de 3200 e $3250 \mathrm{kcal}$ de EM, para frangos de corte tipo industrial. Segundo Noy e Sklan (2002), algumas pesquisas comprovaram que o aumento nos níveis energéticos das dietas promove incremento no ganho de peso de frangos de corte.

Tabela III. Desempenho zootécnico de frangos da linhagem Caipira Francês Barré alimentados com rações contendo diferentes níveis de energia metabolizável (1 a 90 dias de idade). (Production performance of broiler strain Caipira French Barré fed diets containing different levels of metabolizable energy ( 1 to 90 days old)).

\begin{tabular}{|c|c|c|c|c|}
\hline & $\begin{array}{l}\text { Peso médio } \\
\text { (g) }\end{array}$ & $\begin{array}{c}\text { Consumo } \\
\text { de ração }(g)\end{array}$ & $\begin{array}{c}\text { Ganho de peso } \\
\text { (g/ave/dia) }\end{array}$ & $\begin{array}{c}\text { Conversão } \\
\text { alimentar }\end{array}$ \\
\hline \multicolumn{5}{|l|}{1 - 28 dias } \\
\hline T1 - $3100 \mathrm{kcal}$ de EM/kg & $444,00^{a}$ & $913,00^{\mathrm{a}}$ & $14,65^{a}$ & $2,27^{a}$ \\
\hline T2 - $3200 \mathrm{kcal}$ de EM/kg & $506,00^{a}$ & $953,25^{a}$ & $16,85^{a}$ & $2,03^{a}$ \\
\hline T3 - $3300 \mathrm{kcal}$ de EM/kg & $490,75^{a}$ & $858,75^{a}$ & $16,34^{a}$ & $1,92^{a}$ \\
\hline CV $(\%)$ & 16,53 & 11,47 & 12,52 & 22,40 \\
\hline \multicolumn{5}{|l|}{29 - 90 dias } \\
\hline T1 - $3100 \mathrm{kcal}$ de EM/kg & $2772,50^{a}$ & $4979,50^{b}$ & $36,96^{a}$ & $2,15^{a}$ \\
\hline T2 - $3200 \mathrm{kcal}$ de EM/kg & $2951,50^{a}$ & $5981,75^{a}$ & $38,82^{a}$ & $2,44^{a}$ \\
\hline T3 - $3300 \mathrm{kcal}$ de EM/kg & $3071,75^{a}$ & $6195,00^{a}$ & $40,97^{a}$ & $2,39^{a}$ \\
\hline CV $(\%)$ & 6,29 & 6,75 & 7,71 & 6,41 \\
\hline
\end{tabular}


Todavia, outros estudos indicam que esta variável atinge um platô e depois de determinado nível as aves não respondem mais ao aumento de energia das rações.

Ao avaliar a proteína bruta consumida, a energia metabolizada consumida, a eficiência protéica e a eficiência energética das aves foi constatado que não houve efeito significativo das dietas contendo três níveis de energia na fase inicial (tabela IV). Nazareno (2008) avaliando os sistemas de criação confinado e semi-confinado de aves da linhagem Coob 508, alimentadas com dietas contendo 3119 e $3161 \mathrm{kcal} / \mathrm{kg}$ de energia metabolizável, constatou que os sistemas de criação não promoveram alterações marcantes no desempenho e não afetou a eficiência protéica e energética.

A proteína bruta e a energia metabolizada consumida foram influenciadas pelos níveis de energia nas dietas na fase de engorda, sendo que as aves que consumiram 3100 $\mathrm{kcal}$ de $\mathrm{EM} / \mathrm{kg}$ apresentaram uma redução significativa no consumo. A eficiência protéica não foi influenciada pelos níveis de energia nas dietas. Já a eficiência energética foi reduzida com o aumento dos níveis de energia. O nível de $3100 \mathrm{kcal}$ de $\mathrm{EM} / \mathrm{kg}$ nas dietas contribuiu significativamente para melhorar eficiência energética das aves.

Estudando os efeitos da relação energia: proteína sobre o desempenho de frangos de corte na fase de engorda, Reginatto et al. (2000) concluíram que não há vantagens em diminuir a energia da ração no período de 22 a 40 dias de idade, pois ocorre menor ganho de peso e pior conversão alimentar. Por outro lado, dietas iniciais de baixa energia promoveram, na fase subsequente, um período de crescimento acelerado, onde as aves apresentam melhor conversão calórica.

Os dados de rendimento de carcaça e cortes nobres (peito, coxa e sobrecoxa) encontram-se na tabela $\mathbf{V}$. Não houve interação dos diferentes níveis de energia metabolizável sobre nenhuma das variáveis analisadas.

Resultados divergentes foram observados por Neto et al. (2000) que trabalhando com cinco níveis de energia na ração (3000, $3075,3150,3225$ e $3300 \mathrm{kcal}$ de EM/kg de ração) para frangos de corte da linhagem

Tabela IV. Eficiência energética e protéica de frangos da linhagem Caipira francês Barré alimentados com diferentes níveis de energia metabolizável (1 a 90 dias). (Energy efficiency and protein chicken lineage Caipira French Barré fed different levels of metabolizable energy ( 1 to 90 days)).

\begin{tabular}{|c|c|c|c|c|}
\hline $\begin{array}{l}\text { Variáveis } \\
\text { EM (kcal/kg) }\end{array}$ & $\begin{array}{c}\mathrm{T} 1 \\
3100\end{array}$ & $\begin{array}{c}\text { T2 } \\
3200\end{array}$ & $\begin{array}{c}\text { T3 } \\
3300\end{array}$ & $\begin{array}{l}\text { CV } \\
(\%)\end{array}$ \\
\hline \multicolumn{5}{|l|}{1 a 28 dias } \\
\hline Proteína bruta consumida (kg/ave) & $6,98^{a}$ & $7,29^{a}$ & $6,55^{\text {a }}$ & 14,30 \\
\hline Energia metabolizada consumida (g/ave) & $95,14^{\text {a }}$ & $102,77^{a}$ & $95,28^{a}$ & 14,67 \\
\hline Eficiência protéica & $0,49^{a}$ & $0,43^{a}$ & $0,41^{\mathrm{a}}$ & 21,70 \\
\hline Eficiência energética & $0,15^{\mathrm{a}}$ & $0,16^{a}$ & $0,18^{a}$ & 26,72 \\
\hline \multicolumn{5}{|l|}{29 a 90 dias } \\
\hline Proteína bruta consumida (kg/ave) & $15,81^{\mathrm{b}}$ & $18,99^{a}$ & $19,67^{a}$ & 6,29 \\
\hline Energia metabolizada consumida (g/ave) & $245,02^{b}$ & $303,83^{a}$ & $324,50^{a}$ & 6,35 \\
\hline Eficiência protéica & $0,43^{a}$ & $0,49^{a}$ & $0,48^{a}$ & 6,41 \\
\hline Eficiência energética & $0,15^{\mathrm{a}}$ & $0,13^{b}$ & $0,13^{b}$ & 7,32 \\
\hline
\end{tabular}

abMédias seguidas de diferentes letras minúsculas nas linhas diferem estatisticamente entre si pelo teste de Tukey $(p<0,05)$.

Archivos de zootecnia vol. 61, núm. 234, p. 292. 


\section{DESEMPENHO, CARCAÇA E CORTES DE FRANGOS CAIPIRA FRANCÊS BARRÉ}

Hubbard, verificaram que os pesos absolutos e o rendimento dos cortes não foram influenciados pelos níveis de energia estudados, com exceção do rendimento de carcaça, que variou $(p<0,04)$ de forma quadrática, em razão dos níveis de EM.

Ao analisar as diferentes idades de abate das aves, constatou-se que houve diferença significativa para rendimento de coxas, nas aves abatidas aos 84 dias de idade que apresentaram rendimento de $(14,11 \%)$. Mendonça et al. (2008), realizando um experimento com linhagem de crescimento lento ISA Label, machos, observaram que os frangos alimentados com níveis de energia de 2700 a 3300 kcal de EM/ $\mathrm{kg}$ de ração, não apresentaram diferenças significativas para rendimento de carcaça, peito e coxas, quando abatidos aos 70 dias de idade.

Os dados de peso relativo das asas, dorso, pés e cabeça e pescoço encontramse na tabela VI. Houve efeito significativo $(p<0,05)$ apenas para peso relativo do dorso, onde as aves que consumiram $3200 \mathrm{kcal}$ de EM/kg obtiveram melhores resultados aos 90 dias de idade, diferindo significativamente dos outros níveis de energia. Silva et al. (2003) alimentando frangos de corte da linhagem comercial Coob, com dieta contendo 2900,3000 e $3100 \mathrm{kcal}$ de EM/kg encontraram efeito significativo para os pesos relativos de asa e dorso.

Encontrou-se efeito significativo para peso relativo das asas e dorso para as diferentes idades de abate. As aves que

Tabela $V$. Rendimento de carcaça, coxas, sobrecoxas e peito de frangos da linhagem Caipira Francês Barré alimentados com rações contendo diferentes níveis de energia metabolizável, em três idades de abate. (Carcass, thighs, drumsticks and chicken breast Caipira French lineage Barré fed diets containing different levels of metabolizable energy in three slaughter ages).

\begin{tabular}{|c|c|c|c|c|}
\hline & 77 dias & 84 dias & 90 dias & CV $(\%)$ \\
\hline \multicolumn{5}{|l|}{ Carcaça (\%) } \\
\hline $\mathrm{T} 1-3000 \mathrm{kcal}$ de EM$/ \mathrm{kg}$ & $80,90^{\mathrm{aA}}$ & $80,64^{\mathrm{aA}}$ & $78,82^{\mathrm{aA}}$ & 7,69 \\
\hline T2 - $3100 \mathrm{kcal}$ de EM/kg & $80,76^{\mathrm{aA}}$ & $77,29^{\mathrm{aA}}$ & $79,21^{\mathrm{aA}}$ & 4,60 \\
\hline T3 - $3200 \mathrm{kcal}$ de EM/kg & $80,81^{\mathrm{aA}}$ & $82,59^{a A}$ & $79,31^{\mathrm{aA}}$ & 8,81 \\
\hline CV (\%) & 2,98 & 12,90 & 1,60 & \\
\hline \multicolumn{5}{|l|}{ Peito (\%) } \\
\hline T1 - $3000 \mathrm{kcal}$ de EM/kg & $22,71^{\mathrm{aA}}$ & $22,80^{\mathrm{aA}}$ & $23,62^{\mathrm{aA}}$ & 6,66 \\
\hline T2 - $3100 \mathrm{kcal}$ de EM/kg & $22,76^{\mathrm{aA}}$ & $22,73^{\mathrm{aA}}$ & $23,64^{\mathrm{aA}}$ & 7,89 \\
\hline T3 - $3200 \mathrm{kcal}$ de EM/kg & $22,50^{\mathrm{aA}}$ & $22,19^{\mathrm{aA}}$ & $23,23^{\mathrm{aA}}$ & 9,43 \\
\hline CV (\%) & 6,91 & 10,13 & 7,07 & \\
\hline \multicolumn{5}{|l|}{ Coxas (\%) } \\
\hline T1 - $3000 \mathrm{kcal}$ de EM/kg & $13,53^{\mathrm{aA}}$ & $13,79^{\mathrm{aA}}$ & $13,46^{\mathrm{aA}}$ & 5,08 \\
\hline T2 - $3100 \mathrm{kcal}$ de EM/kg & $13,80^{\mathrm{aA}}$ & $13,90^{\mathrm{aA}}$ & $13,82^{\mathrm{aA}}$ & 6,13 \\
\hline T3 - $3200 \mathrm{kcal}$ de EM/kg & $13,32^{\mathrm{aв}}$ & $14,11^{\mathrm{aA}}$ & $13,89^{\mathrm{aAB}}$ & 5,80 \\
\hline CV (\%) & 5,38 & 5,76 & 7,41 & \\
\hline \multicolumn{5}{|l|}{ Sobrecoxas (\%) } \\
\hline $\mathrm{T} 1$ - $3000 \mathrm{kcal}$ de EM/kg & $13,13^{\mathrm{aA}}$ & $13,06^{\mathrm{aA}}$ & $13,45^{\mathrm{aA}}$ & 6,73 \\
\hline T2 - $3100 \mathrm{kcal}$ de EM/kg & $13,33^{\mathrm{aA}}$ & $13,01^{\mathrm{aA}}$ & $13,13^{\mathrm{aA}}$ & 7,11 \\
\hline T3 - $3200 \mathrm{kcal}$ de EM/kg & $12,77^{\mathrm{aA}}$ & $12,47^{\mathrm{aA}}$ & $13,19^{\mathrm{aA}}$ & 8,19 \\
\hline CV (\%) & 8,29 & 7,90 & 5,22 & \\
\hline
\end{tabular}

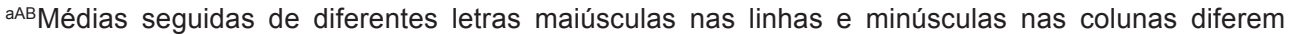
estatisticamente entre si pelo teste de Tukey $(p<0,05)$. 
Tabela VI. Peso relativo das asas, dorso, pés, cabeça e pescoço de frangos da linhagem Caipira Francês Barré alimentados com rações contendo diferentes níveis de energia metabolizável, em três idades de abate. (Relative weight of the wings, back, feet, head and neckof the chicken lineage Caipira French Barré fed diets containing different levels of metabolizable energy in three slaughter ages).

\begin{tabular}{|c|c|c|c|c|}
\hline & 77 dias & 84 dias & 90 dias & CV (\%) \\
\hline \multicolumn{5}{|l|}{ Asas (\%) } \\
\hline $\mathrm{T} 1-3000 \mathrm{kcal}$ de EM/kg & $11,16^{\mathrm{aA}}$ & $10,87^{\mathrm{aA}}$ & $11,03^{\mathrm{aA}}$ & 5,87 \\
\hline T2 - $3100 \mathrm{kcal}$ de EM/kg & $11,34^{\mathrm{aA}}$ & $13,01^{\text {aA }}$ & $11,27^{\mathrm{aA}}$ & 6,09 \\
\hline T3 - $3200 \mathrm{kcal}$ de EM/kg & $11,67^{\mathrm{aA}}$ & $12,47^{\mathrm{aB}}$ & $11,35^{\mathrm{aAB}}$ & 5,32 \\
\hline CV $(\%)$ & 5,72 & 6,81 & 4,06 & \\
\hline \multicolumn{5}{|l|}{ Dorso (\%) } \\
\hline $\mathrm{T} 1-3000 \mathrm{kcal}$ de EM/kg & $22,13^{\mathrm{aA}}$ & $22,03^{\mathrm{aA}}$ & $18,31^{\mathrm{bB}}$ & 10,37 \\
\hline $\mathrm{T} 2-3100 \mathrm{kcal}$ de EM/kg & $19,03^{\mathrm{aA}}$ & $21,81^{\mathrm{aA}}$ & $18,48^{\mathrm{bA}}$ & 17,37 \\
\hline T3 - $3200 \mathrm{kcal} \mathrm{de} \mathrm{EM/kg}$ & $20,68^{\mathrm{aAB}}$ & $22,05^{\mathrm{aA}}$ & $20,29^{a в}$ & 6,50 \\
\hline CV (\%) & 14,15 & 6,50 & 5,19 & \\
\hline \multicolumn{5}{|l|}{ Pés (\%) } \\
\hline T1 - $3000 \mathrm{kcal}$ de EM/kg & $4,97^{\mathrm{aA}}$ & $4,49^{\mathrm{aA}}$ & $4,42^{\mathrm{aA}}$ & 12,29 \\
\hline T2 - $3100 \mathrm{kcal}$ de EM/kg & $5,20^{\mathrm{aA}}$ & $4,68^{\mathrm{aA}}$ & $4,51^{\mathrm{aA}}$ & 14,82 \\
\hline T3 - $3200 \mathrm{kcal}$ de EM/kg & $4,93^{\mathrm{aA}}$ & $4,43^{\mathrm{aA}}$ & $4,38^{\mathrm{aA}}$ & 12,33 \\
\hline CV (\%) & 11,60 & 14,43 & 13,02 & \\
\hline \multicolumn{5}{|l|}{ Cabeça + Pescoço (\%) } \\
\hline T1 - $3000 \mathrm{kcal}$ de EM/kg & $10,12^{\mathrm{aA}}$ & $10,12^{\mathrm{aA}}$ & $10,12^{\mathrm{aA}}$ & 12,68 \\
\hline T2 - $3100 \mathrm{kcal}$ de EM/kg & $10,77^{\mathrm{aA}}$ & $10,77^{\mathrm{aA}}$ & $10,77^{\mathrm{aA}}$ & 10,39 \\
\hline T3 - $3200 \mathrm{kcal}$ de EM/kg & $10,91^{\mathrm{aA}}$ & $10,91^{\mathrm{aA}}$ & $10,91^{\mathrm{aA}}$ & 11,36 \\
\hline CV (\%) & 10,08 & 11,28 & 9,80 & \\
\hline
\end{tabular}

abABMédias seguidas de diferentes letras maiúsculas nas linhas e minúsculas nas colunas diferem estatisticamente entre si pelo teste de Tukey $(p<0,05)$.

consumiram $3200 \mathrm{kcal}$ de EM/kg obtiveram melhores resultados de peso da asa aos 77 dias de idade, porém não diferiu estatisticamente das aves abatidas aos 90 dias de idade. O dorso apresentou efeito significativo para as aves que consumiram $3000 \mathrm{e}$ $3200 \mathrm{kcal}$ de EM/kg.

\section{CONCLUSÕES}

Os níveis de energia nas dietas não interferiram no desempenho zootécnico e

\section{BIBLIOGRAFIA}

Duarte, K.F., Junqueira, O.M., Filardi, R. da S., Laurentiz, A.C. de, Casartelli, E.M., Assuena, V. e Ribeiro, P. de A.P. 2006. Efeito de diferen- no rendimento de carcaça, peito, coxas, sobrecoxas, asas, pés e cabeça + pescoço das aves. O nível de $3200 \mathrm{kcal}$ de EM/kg proporcionou melhor rendimento de dorso. A proteína bruta e a energia metabolizada consumida pelas aves melhoraram com o incremento energético da ração, durante a fase de engorda.

A idade de abate não influenciou no rendimento de carcaça, entretanto as aves abatidas aos 90 dias de idade apresentaram maior rendimento de peito. 


\section{DESEMPENHO, CARCAÇA E CORTES DE FRANGOS CAIPIRA FRANCÊS BARRÉ}

Zootecn, 35: 1992-1998.

Gomes, P.C., Rigueira, D.C.M., Brumano, G., Albino L.F.T., Rostagno, H.S. e Schmidt, M. 2009. Níveis nutricionais de zinco para frangos de corte machos e fêmeas nas fases de crescimento e terminação. Rev Bras Zootecn, 38: 1719-1725.

Kolling, A.V., Kessler, A. de M. e Ribeiro, A.M.L. 2005. Desempenho e composição corporal de frangos de corte alimentados com diferentes níveis de proteína e de aminoácidos ou com livre escolha das dietas. Rev Bras Zootecn, 34: 98-103.

Mello, H.H. de C., Gomes, P.C., Rostagno, H.S., Albino, L.F.T., Souza, R.M. de e Calderano, A.A 2009. Valores de energia metabolizável de alguns alimentos obtidos com aves de diferentes idades. Rev Bras Zootecn, 38: 863-868.

Mendes, M.V., Sousa, J.R., Gomes, A.P. e Almeida, L.N. 2006. Desempenho de frangos de corte, sexados, submetidos a dietas formuladas com níveis crescentes de energia. Cienc Rural, 52: 121-130.

Mendonça, M.O., Sakomura, N.K., Santos, F.R., Freitas, E.R, Fernandes, J.B.K. e Barbosa, N.A.A. 2008. Níveis de energia metabolizável para machos de corte de crescimento lento criados em semiconfinamento. Rev Bras Zootecn, 37: 1433-1440.

Nazareno, A.C. 2008. Influência de diferentes sistemas de criação na produção de frangos de corte industrial com ênfase no bem-estar animal. Dissertação (Mestrado em Engenharia Agrícola). Departamento de Tecnologia Rural. Universidade Federal Rural de Pernambuco.

Neto, A.R. de O., Oliveira, R.F.M., Donzele, J.L., Rostagno, H.S., Ferreira, R.A. e Carmo, H.M. 2000. Níveis de energia metabolizável para frangos de corte no período de 22 a 42 dias de idade mantidos em ambiente termoneutro. Rev Bras Zootecn, 29: 1132-1140.

Noy, Y. and Sklan, D. 2002. Nutrient use in chicks during the first week posthatch. Poultry Sci,
81: 391-399.

Reginatto, M.F., Ribeiro, A.M., Penz Jr., A.M., Kessler, A.M. e Krabbe, E.L. 2000. Efeito da energia, relação energia: proteína e fase de crescimento sobre o desempenho e composição de carcaça de frangos de corte. Rev Bras Cienc Avic, 2: 229-237.

Rostagno, H.S., Albino, L.F.T., Donzele, J.L., Gomes, P.C., Oliveira, R.F., Lopes, D.C., Ferreira, A.S. e Barreto, S.L.T. 2005. Tabela Brasileira de Suínos e Aves. $2^{\circ}$ edição. Universidade Federal de Viçosa.

SAEG. 2007. Sistema para Análise Estatística. Versão 9.1. Fundação Arthur Bernardes. UFV. Viçosa.

Sagrilo, E., Girão, E.S., Barbosa, F.J.V., Ramos, G.M., Azavedo, J.N., Medeiros, L.P., Araujo Neto, R.B. e Leal, T.M. 2003. Validação do sistema alternativo de criação de galinha Caipira. Embrapa Meio Norte. Sistema de produção 1. p. 1.

Santos, A.L. dos, Sakomura, N.K., Freitas, E.R., Fortes, C.M.L.S., Carrilho, E.N. de V.M. e Fernandes, J.B.K. 2005. Estudo do crescimento, desempenho, rendimento de carcaça e qualidade de carne de três linhagens de frango de corte. Rev Bras Zootecn, 34: 1589-1598.

Silva, A.S., Domingues, G.O., Américo, L.M., Costa, M.A. e Alves, C.V. 2003. Desempenho e características de carcaça de frangos de corte alimentados com dietas contendo diferentes níveis de proteína e energia. Rev Bras Agrocien, 12: 201-211.

Takahashi, A.A., Mendes, E.S.P.B, Saldanha, C.C. Pizzolante, K., Pelícia, R.G., Garcia, I.C.L.A e Paz, R.R. 2006. Efeito do sistema de criação sobre o desempenho e rendimento de carcaça de frangos de corte tipo colonial. Arq Bras Med Vet Zoo, 58: 624-632.

Zanusso, J.T. e Dionello, N.J.L. 2003. Produção avícola alternativa: análise dos fatores qualitativos da carne de frangos de corte tipo caipira. Rev Bras Agrocien, 9: 191-194. 